Y. Wang, Z. Qin*, F.-L. Fan, F.-Y. Fan, S.-W. Cao, X.-L. Wu, X. Zhang, J. Bai, X.-J. Yin, L.-L. Tian, L. Zhao, W. Tian, Z. Li, C.-M. Tan, J.-S. Guo, and H. W. Gäggeler

\title{
Gas-phase chemistry of Mo, Ru, W, and Os metal carbonyl complexes
}

Abstract: Metal carbonyl complexes were used for studying the gas-phase chemical behavior of $\mathrm{Mo}, \mathrm{Ru}, \mathrm{W}$ and Os isotopes with an on-line low temperature isothermal gas chromatography apparatus. Short-lived $\mathrm{Mo}$ and $\mathrm{Ru}$ isotopes were produced by a ${ }^{252} \mathrm{Cf}$ spontaneous fission source. Short-lived nuclides of $\mathrm{W}$ and Os were produced using the heavy ion reactions ${ }^{19} \mathrm{~F}+{ }^{159} \mathrm{~Tb}$ and ${ }^{165} \mathrm{Ho}$, respectively. Short-lived products were thermalized in a recoil chamber filled with a gas mixture of helium and carbon monoxide. The carbonyls formed were then transported through capillaries to an isothermal chromatography column for study of the adsorption behavior as a function of temperature. On-line isothermal chromatography (IC) experiments on Teflon (PTFE) and quartz surfaces showed that short-lived isotopes of the listed elements can form carbonyl complexes which are very volatile and interact most likely in physical sorption processes. Deduced adsorption enthalpies of Mo and Ru carbonyls were $-38 \pm$ $2 \mathrm{~kJ} / \mathrm{mol}$ and $-36 \pm 2 \mathrm{~kJ} / \mathrm{mol}$, respectively. These values are in good agreement with literature data, partly obtained with different chromatographic techniques. A validation of the applied Monte Carlo model to deduce adsorption enthalpies with Mo isotopes of different half-lives proved the validity of the underlying adsorption model. The investigations using a gas-jet system coupled to a heavy ion accelerator without any preseparator clearly showed the limitations of the approach. The He and CO gas mixture, which was directly added into the chamber, will result in decomposition of $\mathrm{CO}$ gas and produce some aerosol particles. After the experiment of ${ }^{173} \mathrm{~W}$ and ${ }^{179} \mathrm{Os}$ in the heavy ion experiments, the Teflon column was covered by a yellowish deposit; the adsorption enthalpy of $\mathrm{W}$ and Os carbonyls could therefore not be properly deduced using Monte Carlo simulations.

Keywords: Short-lived radioisotopes, Mo, $\mathrm{Ru}, \mathrm{W}$ and Os carbonyls, Isothermal gas chromatography, Adsorption enthalpy.
*Corresponding Author: Z. Qin, Institute of Modern Physics, Chinese Academy of Sciences, Lanzhou 730000, China, E-mail: qinzhi@impcas.ac.cn

Y. Wang, Z. Qin, F.-L. Fan, F.-Y. Fan, S.-W. Cao, X.-L. Wu, X. Zhang, J. Bai, X.-J. Yin, L.-L. Tian, W. Tian, Z. Li, C.-M. Tan, J.-S. Guo, H. W. Gäggeler: Institute of Modern Physics, Chinese Academy of Sciences, Lanzhou 730000, China

Y. Wang, L.-L. Tian: School of Nuclear Science and Technology, Lanzhou University, Lanzhou 730000, China

Y. Wang, F.-Y. Fan, S.-W. Cao, X. Zhang, W. Tian: University of Chinese Academy of Sciences, Beijing 100049, China

H. W. Gäggeler: Paul Scherrer Institut, CH-5232 Villigen, Switzerland

\section{Introduction}

Metal carbonyl-complexes are characteristic for $d$ elements and are well-known to be volatile. These compounds provide a chance to investigate in future several superheavy elements in the gas-phase. In macrochemistry, formation of carbonyls is only possible at high pressure and temperature $[1,2]$. However, volatile ${ }^{99} \mathrm{Mo}(\mathrm{CO})_{6}$ [3], ${ }^{104} \mathrm{Mo}(\mathrm{CO})_{6}$ [4] and ${ }^{105} \mathrm{Mo}(\mathrm{CO})_{6}$ [5], were synthesized at ambient temperature and pressure in hot-atom reactions in neutron-induced fission of $\left({ }^{235} \mathrm{U}_{2} \mathrm{O}_{3}\right)$ mixed with $\mathrm{Cr}(\mathrm{CO})_{6}$ solid powder. Recently, volatile carbonyl complexes have been formed with recoiling fission products in-situ in a CO gas atmosphere at the TRIGA Mainz reactor in neutron-induced fission of ${ }^{235} \mathrm{U}$ and ${ }^{249} \mathrm{Cf}$, respectively, as well as in the heavy ion reaction ${ }^{24} \mathrm{Mg}+{ }^{144} \mathrm{Sm}$ behind the gas-filled magnetic separator TASCA [6-8]. These experiments paved the way to study carbonyl complexes in online experiments with short-lived isotopes of group V to IX of the Periodic Table. Deduced adsorption enthalpies of observed carbonyls with used chromatographic columns indicated that these molecules are indeed very volatile, i.e. gaseous at ambient conditions. Both isothermal chromatography (IC) and thermochromatography (TC) techniques were applied in their study $[7,8]$. 
All isotopes of superheavy elements (i.e. transactinides with atomic numbers $Z>103$ ) are short-lived and available only at a level of one-atom-at-a-time. Experimental systems used to study their chemical properties are therefore preferentially tested with short-lived isotopes of homologous elements of the Periodic Table. Some of those homologues can be produced in nuclear fission processes with a ${ }^{252} \mathrm{Cf}$ source [9]. Californium-252 has a $3.11 \%$ spontaneous fission branch and a half-life of about $2.6 \mathrm{a}$. The asymmetric fission mode of ${ }^{252} \mathrm{Cf}$ leads to two peaks in the mass distribution ranging from 95 to 120 atomic mass units (amu) and 130 to $155 \mathrm{amu}$, respectively. Hence, neutronrich isotopes of elements in the regions of $\mathrm{Sr}$ to $\mathrm{Pd}$ and of $\mathrm{Sn}$ to Nd are formed [9]. Among those elements, isotopes of Mo and Ru serve as homologous elements of superheavy elements Sg (106) and Hs (108), respectively. These products are formed with much higher independent yields in spontaneous fission of ${ }^{252} \mathrm{Cf}$ compared to neutron-induced fission of ${ }^{235} \mathrm{U}$ at, e.g., a research reactor. The reason is the well known shift of the light mass peak towards heavier products when going from ${ }^{235} \mathrm{U}$ to ${ }^{252} \mathrm{Cf}$ fission.

Heavy ion fusion reactions are also an excellent tool to produce short-lived isotopes of nearly all elements. The spectrum of formed elements is much narrower compared to synthesis of tracer nuclides via fission. Recently, the development of gas-filled recoil separators plays an important role in nuclear physics and chemistry experiments in the SHE region. The advantages of gas-filled recoil separators are the removal of primary beam particles, and reduction of unwanted transfer products which may interfere with or obscure the detection of desired products in nuclear decay spectroscopy $[10,11]$.

In the present work, firstly the ${ }^{252} \mathrm{Cf}$ source of the Institute of Modern Physics (IMP) served as a source of shortlived fission products which were thermalized in a recoil chamber filled with a gas mixture of helium and carbon monoxide. The carbonyls formed were then transported through capillaries to an isothermal chromatography column for study of the adsorption behavior as a function of temperature. The adsorption enthalpies of Mo and $\mathrm{Ru}$ carbonyls were obtained using well-known Monte Carlo models. Secondly, isotopes of $\mathrm{W}$ and Os were formed in heavy ion reactions between a ${ }^{19} \mathrm{~F}$ beam and ${ }^{159} \mathrm{~Tb}$ and ${ }^{165}$ Ho targets, respectively, at the sector focused cyclotron (SFC) of IMP. Due to the limited conditions, this experiment was performed at an accelerator without any preseparator. A gas mixture of $\mathrm{He}$ and $\mathrm{CO}$ was added into the recoil chamber directly and carbonyls of $\mathrm{W}$ and Os may be formed. Again the behavior of their carbonyls was investi- gated to compare it with that of the homologous elements Mo (for $\mathrm{W}$ ) and $\mathrm{Ru}$ (for Os), respectively.

Therefore this study aims at a) performing a first independent confirmation of a recently observed surprising formation of carbonyls of d-elements with $\mathrm{CO}[7,8], \mathrm{b})$ to verify the quality of the applied Monte Carlo modeling of observed chromatograms in an isothermal device using Mo isotopes of different half-lives, and c) to study whether it is possible to synthesize carbonyls in a collecting chamber connected directly to heavy ion accelerator without any preseparator. This latter attempt would enable synthesis of superheavy element carbonyls with much higher overall yields since a relatively thick target could be used and any loss caused by transmission through a separator could be avoided.

\section{Experimental}

Figure 1 shows the schematics of the experimental set-up used in the experiment with the ${ }^{252} \mathrm{Cf}$ source. High-purity He gas (99.999\%, Hefei Cryogenic Vacuum Nutech Company Limited, China) and high-purity CO gas (99.999\%, Beijing Ya'nan Gas Technology Company Limited, China) were mixed by mass flow controllers before passing through a cylindrical chamber with an inner diameter (i.d.) of $5.5 \mathrm{~cm}$ which had a bell-shaped outlet facing a ${ }^{252} \mathrm{Cf}$ source at a variable distance. Studies were performed at a distance of $10 \mathrm{~cm}$ between the outlet and the ${ }^{252} \mathrm{Cf}$ source. Helium served as carrier gas to which $\mathrm{CO}$ was added as reactive gas to reach a total gas flow rate of $1 \mathrm{~L} / \mathrm{min}$. The pressure in the recoil chamber was about $1.2 \mathrm{~atm}$. The ${ }^{252} \mathrm{Cf}$ source was prepared about 10 years ago by electrodepositing $0.5 \mu \mathrm{g}$ of ${ }^{252} \mathrm{Cf}$ on a stainless steel disk [12]. Volatile metal carbonyls were synthesized in situ in the recoil chamber and then transported through a $4 \mathrm{~m}$ long Teflon (PTFE) capillary (i.d. $=2 \mathrm{~mm}$ ) to the isothermal chromatography device.

Figure 2 depicts the experimental set-up used in studies at the heavy ion accelerator. Tb or Ho targets of about $0.7 \mathrm{mg} / \mathrm{cm}^{2}$ thickness were prepared by molecular plating on a $19 \mu \mathrm{m}$ thick Be foil. The dimension of the collecting chamber was $5 \mathrm{~cm}$ (dia.) and $13 \mathrm{~cm}$ (length). The $\mathrm{He}$ gas pressure in the chamber was about $1.2 \mathrm{~atm}$. At the entrance of the chamber a double window system was mounted with a $2.3 \mathrm{mg} / \mathrm{cm}^{2}$ thick HAVAR entrance foil, followed by a He cooling gas prior to entering the Be backing foil. The beam energy of ${ }^{19} \mathrm{~F}$ was $125 \mathrm{MeV}$ which resulted in a center of target (cot) energy of $101 \mathrm{MeV}$ after passing through the metal foils and the cooling gas. At this incident energy, the excitation function of the ${ }^{159} \mathrm{~Tb}$ 


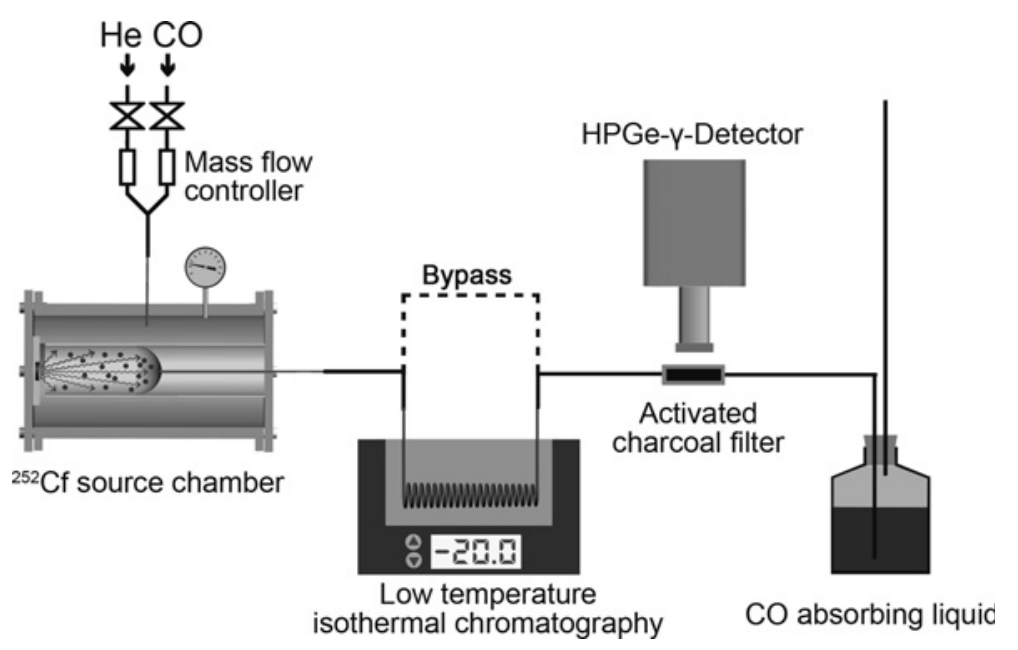

Fig. 1: Schematics of the experimental setup used in the ${ }^{252} \mathrm{Cf}$ experiments. The whole system consists of (i) a gas-jet unit including mass flow controllers, (ii) $\mathrm{a}^{252} \mathrm{Cf}$ SF source installed inside a recoil chamber shielded with lead and paraffin blocks, (iii) a low temperature on-line isothermal gas chromatography apparatus including a low temperature circulating pump with ethyl alcohol as a medium, (iv) an HPGe- $\gamma$-detector and a $5 \mathrm{~cm}$ long activated charcoal filter shielded with lead blocks, and finally, (v) a tail gas treating unit including a CO absorbing liquid.

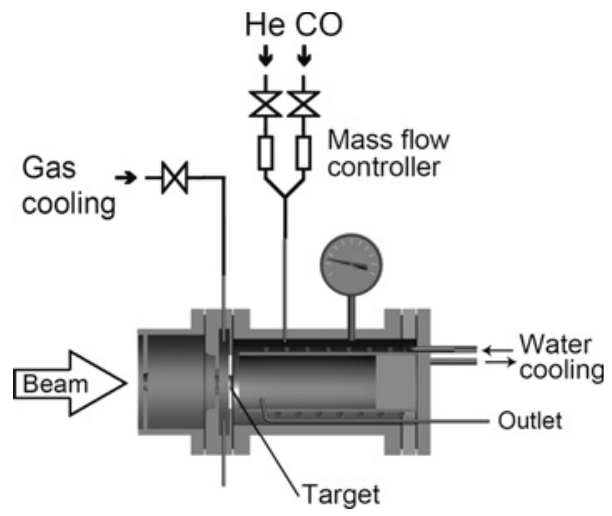

Fig. 2: Gas-jet chamber used in the ${ }^{19} \mathrm{~F}$ experiments. The beam passed through a double window system prior to entering the target. Carbonyl formation occurs in the chamber which is also influenced by the beam. All other components of the set-up were identical to those depicted in Figure 1.

$\left({ }^{19} \mathrm{~F}, 5 n\right){ }^{173} \mathrm{~W}\left(T_{1 / 2}=7.6 \mathrm{~min}\right)$ reaction as well as the ${ }^{165} \mathrm{Ho}\left({ }^{19} \mathrm{~F}, 5 n\right){ }^{179} \mathrm{Os}\left(T_{1 / 2}=6.3 \mathrm{~min}\right)$ reaction exhibits a cross section of about $350 \mathrm{mb}$. The average beam intensity as particle current was about 60 particle-nA. At the exit of the chamber the volatile products were transported with the He carrier gas through a $5 \mathrm{~m}$ long Teflon capillary to the isothermal chromatography device.

Inside the isothermal chromatography device a $2 \mathrm{~m}$ long column (i.d. $=2 \mathrm{~mm}$ ) made of Teflon (PTFE) or quartz was kept at a variable temperature. The chromatography column was positioned in a low temperature cooling circulating unit (model No: DFY-5/80 ${ }^{\circ} \mathrm{C}$, Zhengzhou Yarong Instrument Company Limited, China). The isothermal tem- perature of this unit could be varied in 10 degree steps from $0{ }^{\circ} \mathrm{C}$ to $-80^{\circ} \mathrm{C}$. After passing through this chromatography column, the still volatile carbonyl complexes were transported through a $1 \mathrm{~m}$ long Teflon capillary to an activated charcoal filter (glass tube, i.d. $=4 \mathrm{~mm}$, length $=$ $5 \mathrm{~cm}$, including $0.8 \mathrm{~g}$ of activated charcoal blocked with absorbent cotton on both sides) facing an HPGe- $\gamma$-detector (type EG\&G Ortec GEM- 30200-P with a relative efficiency of $30 \%$ ). The energy resolution (FWHM) was $2.27 \mathrm{keV}$ at $1332 \mathrm{keV} \gamma$-ray energy. Hence, the total transport time from the chamber in the ${ }^{252} \mathrm{Cf}$ experiments to the activated charcoal filter was estimated to be less than $14 \mathrm{~s}$ on the basis of the gas flow rates. In the heavy ion experiments the total transport time was less than $17 \mathrm{~s}$. After each experiment the activated charcoal filter was replaced. The tail gas was bubbled through a cuprous chloride/ammonia solution to absorb the poisonous excess CO gas, before discharge into a fume hood.

$\gamma$-ray spectra were measured, i) of fission products collected with a steel plate positioned opposite to the ${ }^{252} \mathrm{Cf}$ fission source to provide information on the total yield of fission products; however, in an offline mode and ii) of the activated charcoal filter in an online mode (see Figure 1). In the experiments at the heavy ion accelerator no direct catch measurement was made. Most measurements were performed with the same counting time of $30 \mathrm{~min}$, in some cases extended to $2 \mathrm{~h}$ to improve the counting statistics. 


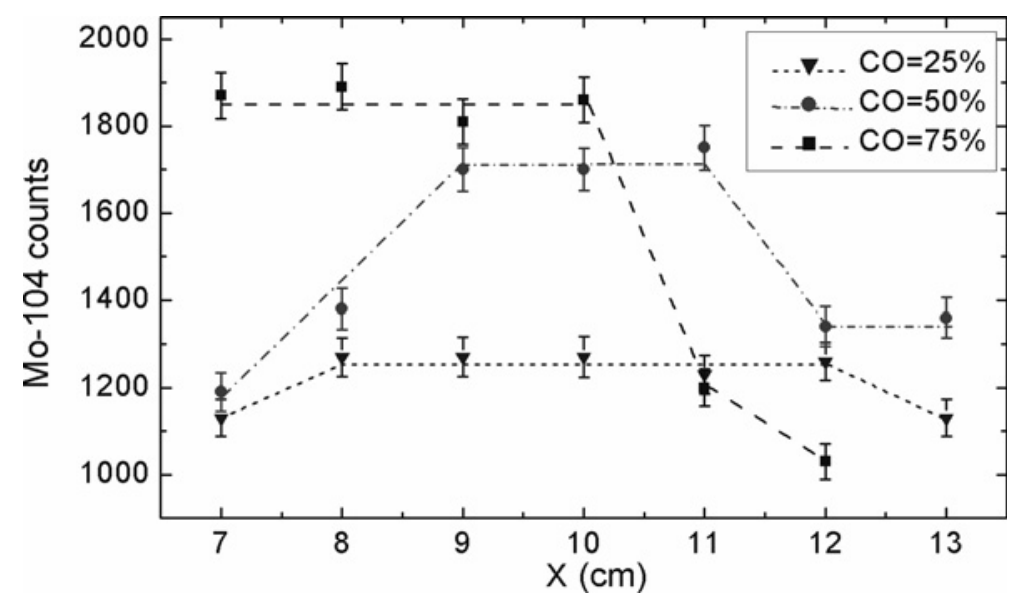

Fig. 3: Yield of ${ }^{104}$ Mo with different distances $(X)$ between the outlet of the capillary and the source at different CO concentrations.

\section{Results and discussion}

The recoil ranges of the fission products inside of the collecting chamber (see Figure 1) had an important effect on their yield. Hence, before the experiment the optimum distance between the outlet of the capillary and the source was determined. The results for ${ }^{104} \mathrm{Mo}$ are shown in Figure 3. $\mathrm{X}$ denotes the distance between the ${ }^{252} \mathrm{Cf}$ fission source and the exit of the capillary. In these experiments the low temperature chromatography unit was bypassed (see Figure 1). Figure 3 shows that the $\mathrm{CO}$ concentration in the gas influenced the value of $\mathrm{X}$ and the maximal counts of ${ }^{104} \mathrm{Mo}$ with $50 \%$ CO are almost equal to those with $75 \%$ $\mathrm{CO}$. Hence, the optimum distance $\mathrm{X}$ as $10 \mathrm{~cm}$ was selected for further experiments (He: $\mathrm{CO}=1: 1)$.

Using ${ }^{104} \mathrm{Mo}$, the relative yield curve of Mo-carbonyls, presumably of $\mathrm{Mo}(\mathrm{CO})_{6}$, as a function of the $\mathrm{CO}$ concentration is shown in Figure 4. We deduce that the relative yield of Mo-carbonyl complexes is $75 \%$ with a CO concentration of $50 \%$, and it reaches $87 \%$ at a CO concentration of $75 \%$, under such an experimental condition. In order to optimize the CO consumption we chose a CO concentration of $50 \%$ in the mixed gas. Therefore, all subsequent experiments were performed with $500 \mathrm{~mL} / \mathrm{min}$ $\mathrm{He}$ and $500 \mathrm{~mL} / \mathrm{min} \mathrm{CO}$, respectively. The relative yield of ${ }^{104} \mathrm{Mo}(\mathrm{CO})_{6}$ was given as more than $80 \%$ compared to an on-line experimental $\gamma$-spectrum by using $\mathrm{KCl}$ aerosol (obtained at about $690^{\circ} \mathrm{C}$ ) and $1 \mathrm{~L} /$ min pure carrier gas.

Figure 5a shows the $\gamma$-ray spectrum obtained in the direct catch experiment where fission products were collected for $30 \mathrm{~min}$ and measured for $30 \mathrm{~min}$. According to the previous experiment and literature data, only the main $\gamma$-ray lines in the $\gamma$-ray spectrum are identified roughly to ${ }^{103} \mathrm{Mo},{ }^{104} \mathrm{Mo},{ }^{103} \mathrm{Nb},{ }^{107} \mathrm{Tc},{ }^{105} \mathrm{Tc},{ }^{132} \mathrm{Te},{ }^{105} \mathrm{Tc},{ }^{105} \mathrm{Mo}$, ${ }^{105} \mathrm{Ru},{ }^{141} \mathrm{Ba},{ }^{134} \mathrm{Te},{ }^{139} \mathrm{Xe},{ }^{142} \mathrm{Ba},{ }^{138} \mathrm{Xe},{ }^{101} \mathrm{Tc},{ }^{146} \mathrm{Ce}$,

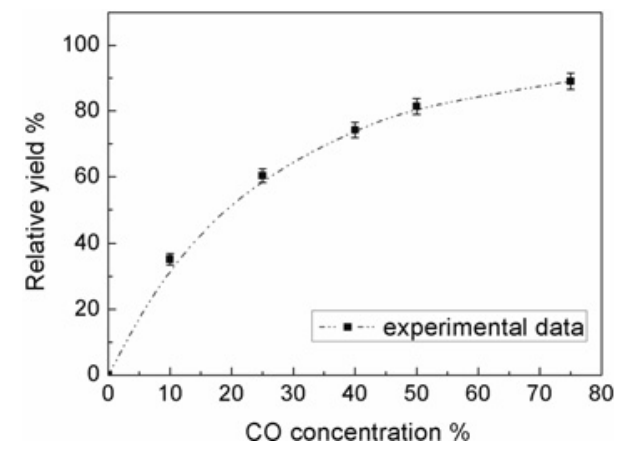

Fig. 4: Relative yield curve of ${ }^{104} \mathrm{Mo}(\mathrm{CO})_{6}$ as a function of the $\mathrm{CO}$ concentration in the He carrier gas.

${ }^{104} \mathrm{Tc},{ }^{146} \mathrm{Pr}$ etc. Figure $5 \mathrm{~b}$ depicts a measurement of the activated charcoal filter with pure $\mathrm{He}$ as carrier gas. Only peaks of gaseous Xe isotopes can be seen. Figure $5 c$ shows the $\gamma$-ray spectrum obtained from the activated charcoal filter with $1 \mathrm{~L} / \mathrm{min}$ mixture gas $(\mathrm{He}: \mathrm{CO}=1: 1)$. In addition to the peaks of gaseous Xe isotopes, only $\gamma$ peaks of short lived isotopes of Mo, Tc, Ru and Rh could be observed. $\gamma$-rays of isotopes of $\mathrm{Ba}, \mathrm{Te}$ and $\mathrm{Ce}$, which appear in Figure 5a, are absent in Figure 5c, and we thus exclude aerosol transport in the carbonyl experiments by using the ${ }^{252} \mathrm{Cf}$ source. Volatile compounds, identified as carbonyl complexes were formed when $1 \mathrm{~L} / \mathrm{min}$ mixture gas (He: $\mathrm{CO}$ $=1: 1)$ was used.

One should, however, be aware that in the fission process many nuclides of an isobar are formed. Table 1 summarizes the calculated fractional independent yields in spontaneous fission (SF) of ${ }^{252} \mathrm{Cf}$ [13]. As an example, the nuclide ${ }^{104} \mathrm{Tc}$ which was well observed in the $\gamma$-ray spectrum was produced with a low yield as primary fission product but formed mainly via $\beta$-decay of its precursors ${ }^{104} \mathrm{Mo},{ }^{104} \mathrm{Nb}$ and ${ }^{104} \mathrm{Zr}$. Therefore, not all observed iso- 


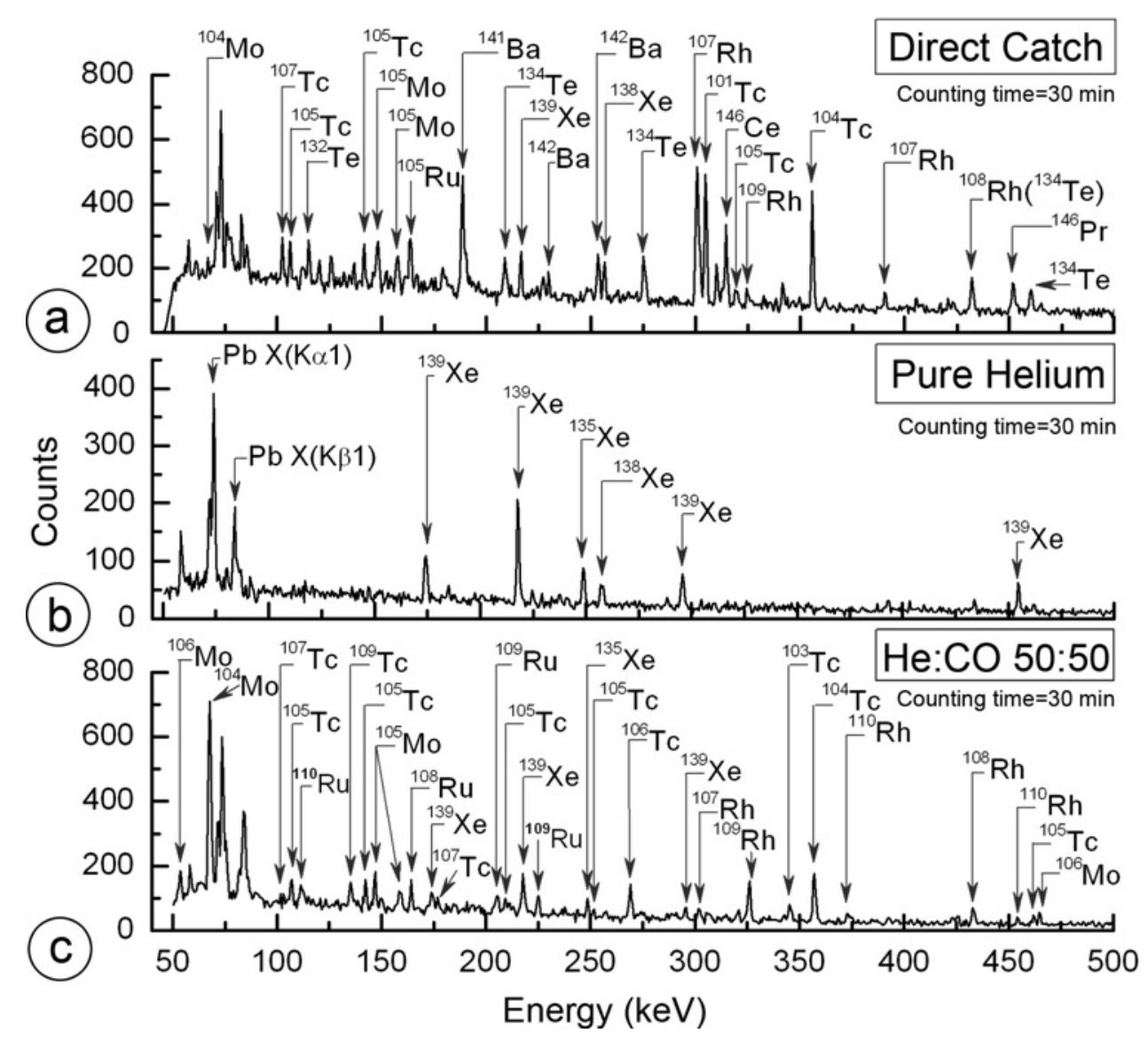

Fig. 5: $\gamma$-ray spectra of a direct catch collected during $30 \mathrm{~min}$ (a), of products collected on the charcoal trap with pure He (b) and of products collected on the charcoal trap with a $1: 1 \mathrm{He} / \mathrm{CO}$ gas mixture (c).

Table 1: Fractional independent yields of fission fragments from the $\mathrm{SF}$ decay of ${ }^{252} \mathrm{Cf}$ in \% (from [13], approx. values because not corrected for prompt neutron emission).

\begin{tabular}{lccccccc}
\hline Isobar & $\mathbf{Y}$ & $\mathbf{Z r}$ & $\mathbf{N b}$ & $\mathbf{M o}$ & $\mathbf{T c}$ & $\mathbf{R u}$ & $\mathbf{R h}$ \\
\hline 104 & 0.4 & 21 & 67 & 12 & 0.1 & & \\
106 & & 1.2 & 35 & 58 & 5.3 & & \\
108 & & & 2 & 51 & 44 & 2 & \\
110 & & & & 8 & 63 & 28 & 0.8 \\
\hline
\end{tabular}

topes represent the chemical properties of the corresponding element. A chemical interpretation of observed chromatographic properties requires (i) an analysis of the nuclide's half-life, (ii) a comparison with the independent fission yield (see Table 1), (iii) a knowledge of the transport time from the collecting chamber to the activated charcoal filter, and (iv) a knowledge of fission isobar members that can form volatile metal carbonyls.

As ${ }^{106} \mathrm{Mo}$, with a half-life of $8.4 \mathrm{~s}$, was detected but not several fission nuclides with half-lives of a few seconds, we conclude that our system had a separation time in the same order of magnitude as the half-life of ${ }^{106} \mathrm{Mo}$, in agreement with estimates made on the basis of the gas flow rates (see above). In order to eliminate fluctuations in transport yield we normalized all measured count rates to that of ${ }^{139} \mathrm{Xe}$ which is independent of carbonyl formation.

A VB code was compiled for Monte Carlo simulation of the yield curves [14], based on a microscopic model by Zvara [15]. Figure 6 shows the relative yield $v s$. isothermal temperature for ${ }^{104} \mathrm{Mo}(\mathrm{CO})_{6}$ on a Teflon surface using the isothermal cooling unit (see Figure 1). The $T_{50 \%}$ value of ${ }^{104} \mathrm{Mo}$ was $-67^{\circ} \mathrm{C}$. The solid line was the result of a MonteCarlo simulation [15] of the experimental data with an enthalpy of adsorption $\Delta H_{\text {ads }}$ of $-38 \mathrm{~kJ} / \mathrm{mol}$. The dashed lines indicate the error range of $\pm 1 \mathrm{~kJ} / \mathrm{mol}$. This error does not include any systematic uncertainty.

Relative yields of ${ }^{104-106} \mathrm{Mo}(\mathrm{CO})_{6},{ }^{105} \mathrm{Tc}(\mathrm{CO})_{x}$ and ${ }^{109} \mathrm{Ru}(\mathrm{CO})_{x}$ on a quartz surface are shown in Figure 7. We assume that ${ }^{104} \mathrm{Mo}\left(T_{1 / 2}=60 \mathrm{~s}\right),{ }^{105} \mathrm{Mo}\left(T_{1 / 2}=35.6 \mathrm{~s}\right)$ and ${ }^{106} \mathrm{Mo}\left(T_{1 / 2}=8.4 \mathrm{~s}\right)$ were transported in the form of $\mathrm{Mo}(\mathrm{CO})_{6}$ to the filter. The $T_{50 \%}$ values of the different isotopes of Mo depend on their half-lives (see Figure 7a), 


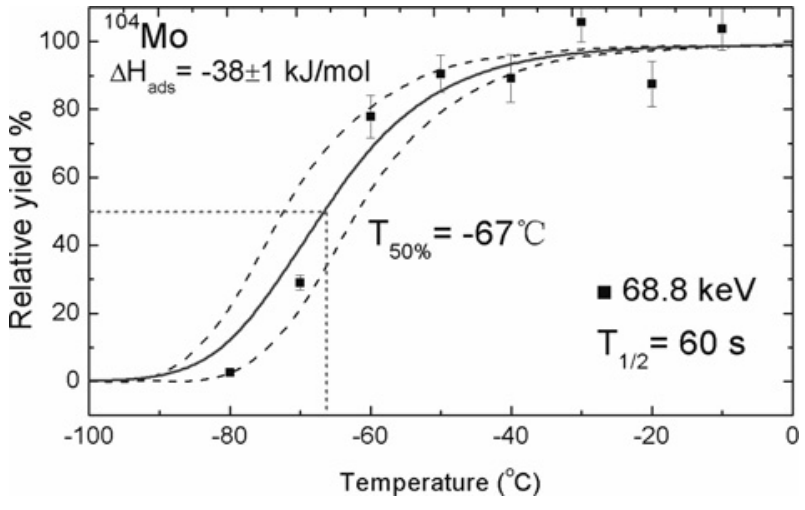

Fig. 6: Relative yield of ${ }^{104} \mathrm{Mo}(\mathrm{CO})_{6}$ as a function of isothermal temperature on a Teflon surface.

as expected from the Monte Carlo model prediction [15] and similar to an observation made in the study of Tc oxides [12]. As expected, the adsorption enthalpies deduced from the three curves are similar with $-39 \pm 1 \mathrm{~kJ} / \mathrm{mol}$, representing the chemical behavior of Mo. Though ${ }^{105} \mathrm{Mo}$ and ${ }^{105} \mathrm{Tc}$ have obviously different half-lives $(35.6 \mathrm{~s} \mathrm{vs}$. $7.6 \mathrm{~min}$ ), the $T_{50 \%}$ values are identical (see Figure $7 \mathrm{~b}$ ). This result can be explained as follows: maybe ${ }^{105} \mathrm{Tc}$ was formed in the charcoal filter by $\beta$-decay of the transported precursor ${ }^{105} \mathrm{Mo}$. If the kinetics to form a volatile Tc compound is significantly slower than that of forming a volatile Mo compound, this as well might result in identical $T_{50 \%}$ values for ${ }^{105} \mathrm{Mo}$ and ${ }^{105} \mathrm{Tc}$. The deduced adsorption enthalpy on the quartz surface for Mo carbonyls is $-39 \pm 1 \mathrm{~kJ} / \mathrm{mol}$, which is consistent with literature values of $-42.5 \pm 2.5 \mathrm{~kJ} / \mathrm{mol}$ and $-36 \pm 8 \mathrm{~kJ} / \mathrm{mol}$, respectively, obtained by IC and TC techniques on quartz $[7,8]$.

${ }^{109} \mathrm{Ru}$ is a good representative of the chemical behavior of ruthenium due to the short half-lives of the precursors ${ }^{109} \mathrm{Tc}\left(T_{1 / 2}=0.86 \mathrm{~s}\right)$ and ${ }^{109} \mathrm{Mo}\left(T_{1 / 2}=0.53 \mathrm{~s}\right)$, respectively, which are too short to be transported with significant yield to the chromatography column. Because of a low independent fission yield the decay product of ${ }^{109} \mathrm{Ru}$, i.e. ${ }^{109} \mathrm{Rh}$, also represents the chemical behavior of Ru. Moreover, due to the low independent fission yield, the measuring time for ${ }^{109} \mathrm{Ru}$ was extended to $2 \mathrm{~h}$ in order to get better statistics. This case is similar to the situation for ${ }^{105} \mathrm{Tc}$ and ${ }^{105} \mathrm{Mo}$. Unfortunately, we have not identified any $\gamma$-line of an isotope of Tc that could be used to determine the chemical behavior of this element.

In summary, the nuclides used to study the chemical behaviour of Mo and Ru are listed in Table 2. Evidently, no difference in adsorption enthalpy was observed for the two surfaces of quartz and Teflon which points to a physical sorption process. At present, we cannot prove which car-
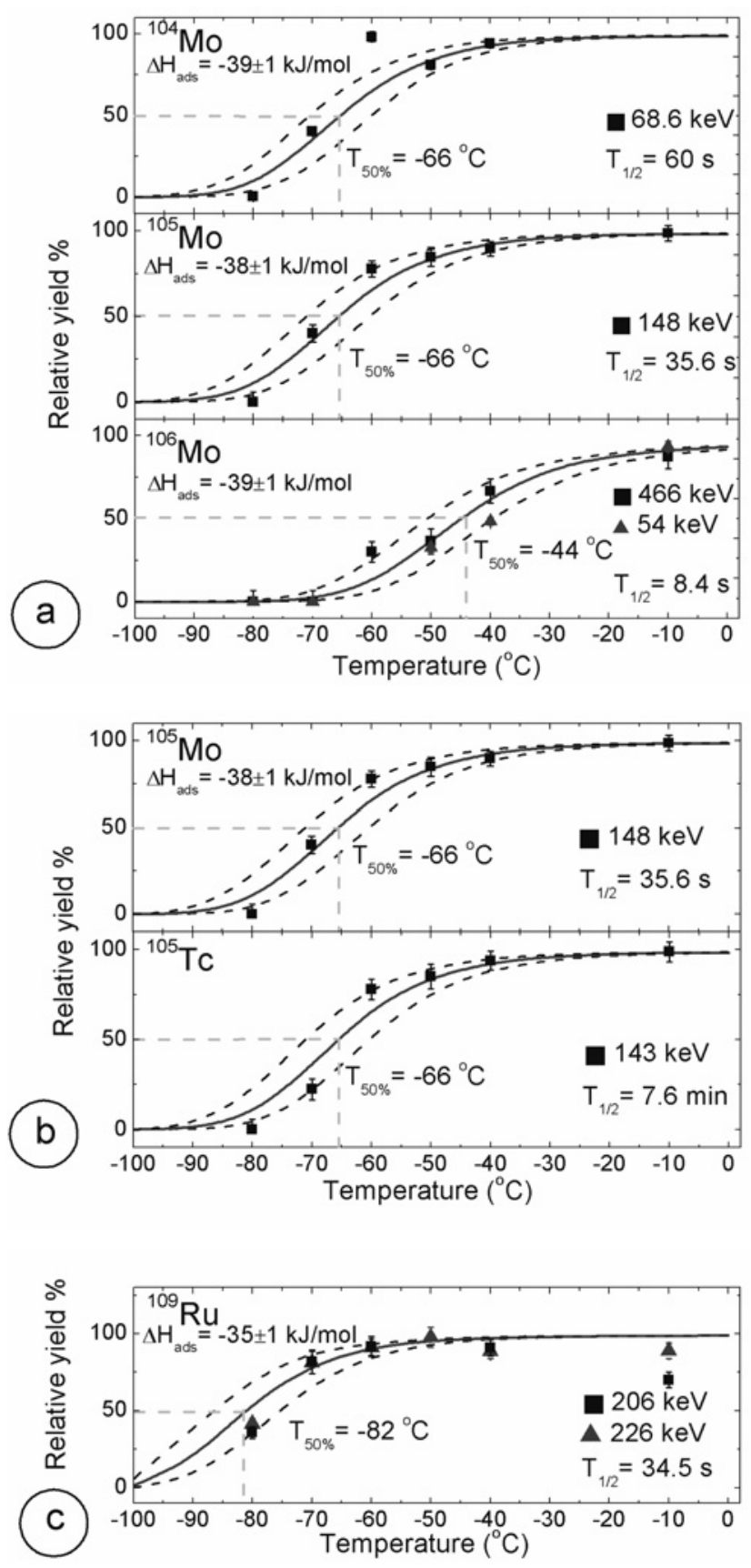

Fig. 7: Isothermal chromatography curves of different isotopes of Mo and Ru on quartz surface. The solid lines represent Monte Carlo simulations adapted to the experimental data. Figs. $7 \mathrm{a}$ and $7 \mathrm{~b}$ represent adsorption of molybdenum on quartz; while Figure $7 c$ represents that of ruthenium (see text). Figure 7a shows the expected shift of the break-through curve as a function of half-life.

bonyl compounds were formed. Further investigations are needed to clarify the speciation.

After the experiment of ${ }^{173} \mathrm{~W}$ and ${ }^{179} \mathrm{Os}$, the Teflon column was covered by a yellowish deposit at a temperature below about $-40^{\circ} \mathrm{C}$. At higher temperatures this 
Table 2: Adsorption enthalpies of carbonyl complexes of molybdenum, technetium and ruthenium on Teflon and quartz surfaces. (Some isotopes of different elements may represent the chemical properties of the listed element, see Figure $7 \mathrm{~b}$ ).

\begin{tabular}{|c|c|c|c|}
\hline \multirow[t]{2}{*}{ Elements } & \multirow[t]{2}{*}{ Isotopes } & \multicolumn{2}{|c|}{$\Delta H_{\text {ads }}$ on different materials } \\
\hline & & Teflon & Quartz \\
\hline \multirow[t]{5}{*}{ Mo } & ${ }^{104} \mathrm{Mo}$ & $-38 \pm 1 \mathrm{~kJ} / \mathrm{mol}$ & $-39 \pm 1 \mathrm{~kJ} / \mathrm{mol}$ \\
\hline & ${ }^{105} \mathrm{Mo}$ & $-37 \pm 1 \mathrm{~kJ} / \mathrm{mol}$ & $-38 \pm 1 \mathrm{~kJ} / \mathrm{mol}$ \\
\hline & ${ }^{106} \mathrm{Mo}$ & $-37 \pm 1 \mathrm{~kJ} / \mathrm{mol}$ & $-39 \pm 1 \mathrm{~kJ} / \mathrm{mol}$ \\
\hline & ${ }^{104} \mathrm{Tc}$ & $-39 \pm 2 \mathrm{~kJ} / \mathrm{mol}$ & $-39 \pm 1 \mathrm{~kJ} / \mathrm{mol}$ \\
\hline & ${ }^{105} \mathrm{Tc}$ & $-39 \pm 1 \mathrm{~kJ} / \mathrm{mol}$ & $-38 \pm 1 \mathrm{~kJ} / \mathrm{mol}$ \\
\hline \multirow[t]{2}{*}{$\overline{\mathrm{Ru}}$} & ${ }^{109} \mathrm{Ru}$ & $-37 \pm 1 \mathrm{~kJ} / \mathrm{mol}$ & $-35 \pm 1 \mathrm{~kJ} / \mathrm{mol}$ \\
\hline & ${ }^{109} \mathrm{Rh}$ & $-36 \pm 1 \mathrm{~kJ} / \mathrm{mol}$ & $-36 \pm 1 \mathrm{~kJ} / \mathrm{mol}$ \\
\hline
\end{tabular}

deposit was found on the filter mounted behind the column. We assign this deposit to formation of carbon particles, caused by interaction of the beam with the $\mathrm{He} / \mathrm{CO}$ gas. A similar phenomenon has been reported by $\mathrm{Fe}$ doseev et al.[16]. In their work, they mentioned that the $\beta$-diketone was decomposed when $\beta$-diketone vapours were directly added into the target chamber. The yield curve of tungsten on a Teflon column, which was covered with unknown deposit, was measured. The results are shown in Figure 8. Each point was measured for about $30 \mathrm{~min}$. Although W and Os may be formed as volatile carbonyls when $\mathrm{He} / \mathrm{CO}$ gas was added in the heavy ion experiments, the adsorption enthalpy of $\mathrm{W}$ and Os cannot be deduced properly using Monte Carlo simulations, because the Teflon column was covered by a yellowish deposit after the experiment.

Figure 9 shows the $\gamma$-ray spectrum obtained in a measurement of ${ }^{173} \mathrm{~W}$ carbonyls. In addition to the main peaks of ${ }^{173} \mathrm{~W}$, the $\gamma$-ray lines of ${ }^{21} \mathrm{Na},{ }^{25} \mathrm{Na}$ and ${ }^{19} \mathrm{O}$, which were

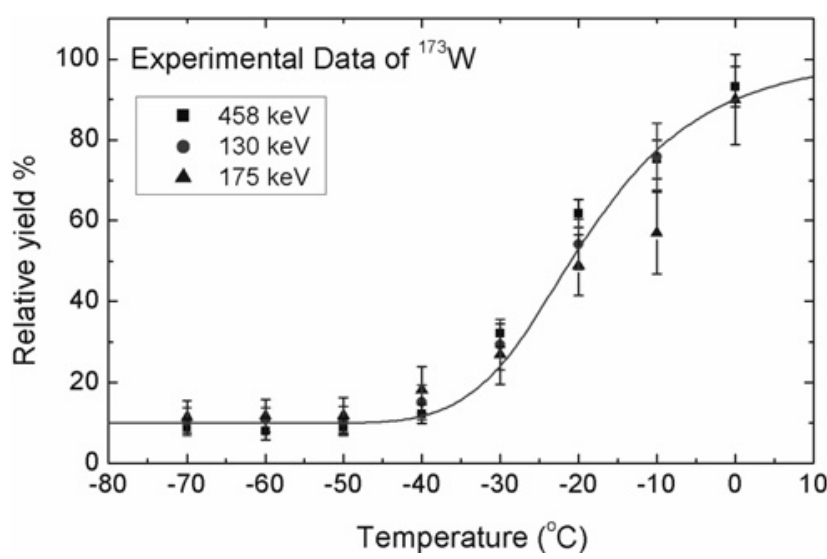

Fig. 8: Yield curve of ${ }^{173} \mathrm{~W}$ in an isothermal experiment on an unclean Teflon surface.

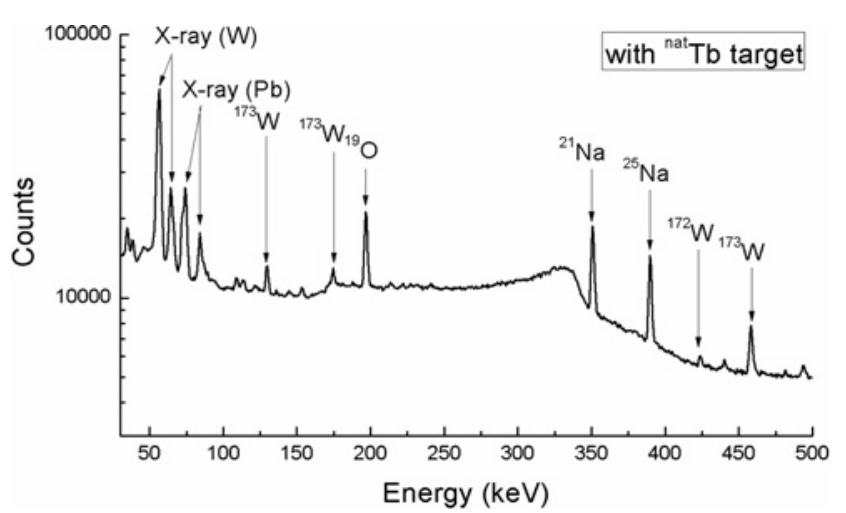

Fig. 9: $\gamma$-ray spectrum obtained in a measurement of $\mathrm{W}$ carbonyls. Besides $\gamma$-lines that can be assigned to isotopes of $\mathrm{W}$, also isotopes of $\mathrm{Na}$ are observed, most likely transported by aerosol particles.

most likely formed in nucleon transfer reaction with the ${ }^{19} \mathrm{~F}$ beam, can also be observed. We normalized all measured count rates to that of ${ }^{19} \mathrm{O}\left(T_{1 / 2}=27.1 \mathrm{~s}\right)$ to eliminate fluctuations in transport yield. However, sodium can only be transported with aerosol particles. So some aerosol particles have been produced in our experiment, which indicates that the beam leads to the decomposition of part of the $\mathrm{CO}$ gas.

To investigate the limitation of the applied technique the yield of ${ }^{173} \mathrm{~W}$ was measured as a function of the beam intensity as particle current (Figure 10). The yield of ${ }^{173} \mathrm{~W}$ increases with the increasing beam intensity and reaches a plateau at about 140 particle-nA. Because more aerosol particles will be produced at high beam intensity, our experiments were carried out at the average beam intensity of about 60 particle-nA.

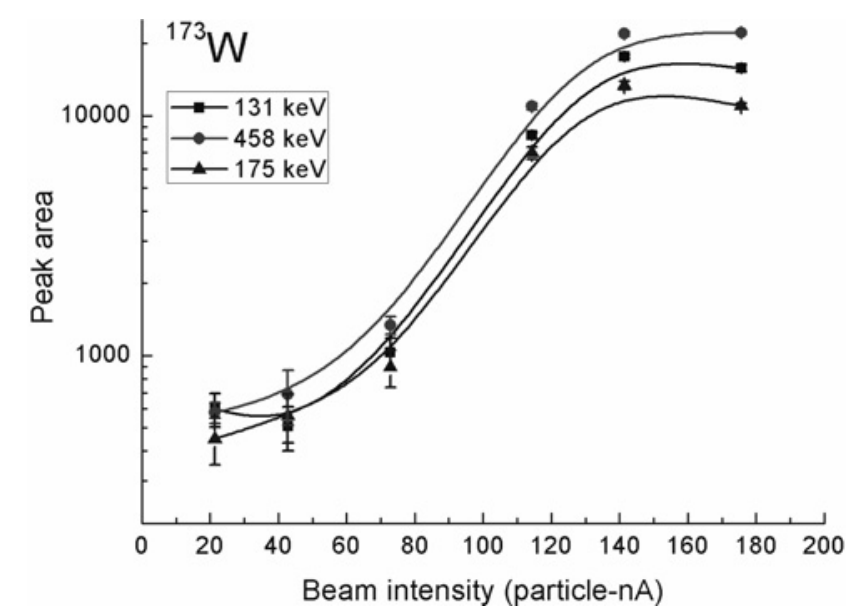

Fig. 10: Yield of ${ }^{173} \mathrm{~W}$ from different $\gamma$-lines as a function of beam intensity. 


\section{Conclusions}

An on-line low temperature isothermal gas chromatography apparatus coupled to a ${ }^{252} \mathrm{Cf}$ SF source at IMP was used to study molybdenum- and ruthenium- carbonyl complexes synthesized with carbon monoxide. Rather similar adsorption enthalpies on Teflon and quartz surfaces for these formed carbonyl complexes were observed which points to a physical sorption process of these compounds in their surface interactions. This work is the first confirmation of a recent discovery that carbonyls can be formed under ambient condition [7, 8]. The measured adsorption enthalpies of Mo carbonyls on quartz surface agree well with literature data [7]. Moreover, the shifts of the break-through curves in the isothermal columns for Mo isotopes of different half-lives prove the validity of the applied model to describe the adsorption process.

In the heavy ion experiments clear limitations were observed when carbonyls were formed in the gas volume containing $\mathrm{CO}$, being heavily influenced by the beam plasma (gas-jet technique). Even though this technique would enable higher overall yields compared to the recently applied investigation of formation of tungsten and osmium carbonyls [7] behind the preseparator TASCA, it is obvious that aerosol formation and beam intensity limitation make this approach not suitable for applications in future superheavy element chemistry experiments. Because the Teflon column was covered by a yellowish deposit after the experiment of $W$ and Os, the adsorption enthalpy of $\mathrm{W}$ and Os cannot be deduced properly using Monte Carlo simulations.

This study also corroborates perspectives for studying the gas chemistry of superheavy elements $\mathrm{Sg}$ and $\mathrm{Hs}$ in a gas volume containing CO.

Acknowledgement: The present work was supported by National Natural Science Foundation of China (Grant No. 20901080, 11079006, 11205216). H. W. G. would like to thank for a grant under the "CAS Visiting Professorship for Senior International Scientists” Program.

Received October 20, 2012; accepted December 27, 2013.

\section{References}

1. Blanchard, A. A.: Chem. Rev. 21, 3-38 (1937).

2. Mond, L., Langer, C., Quincke, F. J.: Chem. Soc., Trans. 57, 749753 (1890).

3. Baumgärtner, F., Reichold, P. : Z. fuer Naturforschung 16, 945948 (1961).

4. Kienle, P., Weckermann, B., Baumgärtner, F., Zahn, U.: Naturwissenschaften 49, 294-295 (1962).

5. Kienle, P., Weckermann, B., Baumgärtner, F.: Naturwissenschaften 49, 295-296 (1962).

6. Niewisch, L.: Neuartige Verbindungsklassen der Transactiniden am Beispiel der Carbonyle und Metallocene der leichteren Homologen. Diploma thesis, Mainz University, Germany (2010).

7. Even, J.: Developments for transactinide chemistry experiments behind the gas-filled separator TASCA. Ph.D.thesis, Mainz University, Germany (2011).

8. Even, J., Yakushev, A., Düllmann, C. E., Dvorak, J.,Eichler, R., Gothe, O., Hild, D., Jäger, E., Khuyagbaatar, J., Kratz, J. V., Krier, J., Niewisch, L., Nitsche, H., Pysmenetska, I., Schädel, M., Schausten, B., Türler, A.,Wienl, N., Wittwer, D.: Inorg. Chem. 51(12), 6431-6433 (2012).
9. Düllmann, C. E., Eichler, B., Eichler, R., Gäggeler, H. W., Jost, D. T., Kindler, U., Piguet, D., Soverna, S., Thorle, P., Trautmann, N., Türler, A.: Nucl. Instrum. Methods Phys. Res., Sect. A 512, 595-605 (2003).

10. Düllmann, C. E.: Nucl. Instrum. Methods Phys. Res., Sect. B 233, 4123-4130 (2008).

11. Semchenkov, A., Brüchle, W., Jäger, E., Schimpf, E., Schädel, M., Mühle, C., Klos, F., Türler, A., Yakushev, A., Belov, A., Belyakova, T., Kaparkova, M., Kukhtin, V., Lamzin, E., Sytchevsky, S.: Nucl. Instrum. Methods Phys. Res., Sect. B 266, 4153-4161 (2008).

12. Lin, M. S., Qin, Z., Lei, F. A., Guo, J. S., Zhang, L. N., Ding, H. J., Fan, F. L., Bai, J., Wu, X. L., Li, X. F.: Radiochimica Acta 98, 321326 (2010).

13. Wahl, A. C.: J. Radioanal. Chem. 55, 111-123 (1980).

14. Eichler. R, University of Bern, Switzerland. priv. comm. (2012).

15. Zvara, I.: Radiochimica Acta.38, 95-101 (1985).

16. Fedoseev, E. V., Aizenberg, M. T., Timokhin, S. N., Travnikov, S. S., Zvara, I., Davydov, A. V., Myasoedov. B. F.: J. Radioanal. Nucl. Chem., Lett. 119(5), 347-354 (1987). 